\title{
Effect of low intensity pulsed ultrasound in activating the mitogen-activated protein kinase signaling pathway and inhibition inflammation cytokine synthesis in chondrocytes
}

\author{
Eun-Jung Kim, Gye-Yeop Kim \\ Department of Physical Therapy, College of Health and Welfare, Dongshin University, Naju, Republic of Korea
}

Objective: Low intensity pulsed ultrasound (LIPUS) has been shown to accelerate cell proliferation and tissue healing in both animal models and clinical trials. However, details of the clinical effects of LIPUS have not been well characterized. The aim of this study was to investigate the effect of LIPUS on mitogen-activated protein kinase (MAPK) activation in rat articular chondrocytes. Design: Cross-sectional study.

Methods: Chondrocyte were cultured in six well cell culture plates for 72 hours at $37^{\circ} \mathrm{C}$ with $5 \% \mathrm{CO}_{2}$, and then exposed to LIPUS at $1.5 \mathrm{MHz}$ frequency and $30-\mathrm{mW} / \mathrm{cm}^{2}$ power. Changes in chondrocyte activities were evaluated in response to oxydative stress in dose-dependent $(0$ and $300 \mathrm{uM})$ and time-dependent $(0-24 \mathrm{hr})$ manner. The cell viability were analyzed using MTT [3-(4.5-dimethylthiazol-2-yl)-2.5 diphenyltetrazolium bromide]. The expression of p38 MAPK was measured using western blotting.

Results: Oxidative stress was induced in rat chondrocytes using hydrogen peroxide $\left(\mathrm{H}_{2} \mathrm{O}_{2}\right)$. The cell viability was decreased in chondrocytes after the $\mathrm{H}_{2} \mathrm{O}_{2}$ dose and time-dependent treatment. The p38 MAPK phosphorylation occurred at a significantly increased rate after $\mathrm{H}_{2} \mathrm{O}_{2}$ treated $(p<0.05)$. Expression of $\mathrm{p} 38$ MAPK was decreased in the $\mathrm{p} 38$ inhibitor groups compared with the oxidative stress-induced chondrocyte damage via the p38 MAPK signaling pathways $(p<0.05)$.

Conclusions: It could be concluded that LIPUS can inhibit oxidative stress-induced chondrocyte damage via the p38 MAPK signaling pathways.

Key Words: Chondrocytes, MAPK, Ultrasound

\section{Introduction}

Osteoarthritis (OA), the most common type of degenerative arthritis, is characterized by marked alterations in the composition factor, structure, and function of joints in the lower extremities [1]. OA is a painful and inflammatory disease that affects an estimated $12 \%-15 \%$ of the population aged 25-74 years in the United States (US) [2]. From the initial stages of OA, pathogenesis involves increased chondrocyte proliferation and the synthesis of matrix proteins, proteinases, cytokines, and other inflammatory cytokines by chondrocytes [3]. Moreover, articular cartilage is difficult to regenerate once damaged.

According to these histological features of cartilage, the first treatment for $\mathrm{OA}$ is aimed at reducing pain and stiffness to allow patients to maintain or recover their mobility and improve their quality of life. The second treatment aims to prevent the progression of cartilage degradation and regenerate damaged articular tissue. OA therapy can be pharmacological, non-pharmacological, or physical, and mechanical stimulation, but it is more commonly a combination of therapies, depending on the patients' state [4-6]. Various methods of mechanical stimulation of chondrocytes have been reported, such as loading with hydrostatic pres-

Received: 16 December, 2013 Revised: 26 May, 2014 Accepted: 13 June, 2014

Corresponding author: Eun-Jung Kim

Department of Physical Therapy, College of Health and Welfare, Dongshin University, 185 Geonjae-ro, Naju 520-714, Republic of Korea Tel: 82-61-330-3390 Fax: 82-61-330-3394 E-mail: ddosuny@hanmail.net

(c) This is an Open-Access article distributed under the terms of the Creative Commons Attribution Non-Commercial License (http://creativecommons.org/licens es/by-nc/3.0) which permits unrestricted non-commercial use, distribution, and reproduction in any medium, provided the original work is properly cited.

Copyright @ 2014 Korean Academy of Physical Therapy Rehabilitation Science 
sure [7], oscillation using a vibrator [8], tensile strain [9], and low-intensity pulsed ultrasound (LIPUS) [10-12]. Mechanical stimulation is an essential factor that promotes the differentiation and proliferation of intact chondrocytes. Many attempts have been made to achieve regeneration of damaged cartilage tissue. The acoustic pressure waves produced by US can be considered high-frequency micromechanical perturbations that may have a direct mechanical effect on exposed cells. LIPUS has been demonstrated in many studies to accelerate cell proliferation and differentiation, the healing process, and fracture repair [13-15]. Chondrocytes are probably the most important cells in the development of osteoarthritic progression [3]. Many studies have reported that chondrocytes are stimulated by LIPUS, which has been widely used in the clinical setting to accelerate the anti-inflammatory and pain relief processes. However, it remains unclear how LIPUS influences the exact mechanism leading to delayed cell degradation during chondrocyte damage in arthritis.

Accordingly, the aim of this study was to elucidate the mechanisms underlying the mechanical activation of chondrocytes and intracellular signaling through the mitogen-activated protein kinase (MAPK) pathways in LIPUS-treated chondrocytes exposed to oxidative stress.

\section{Methods}

\section{Cell culture}

A modified method for harvesting chondrocytes was used as previously described [16]. Chondrocytes were isolated from articular cartilage of 3 week old male Sprague-Dawley rats. Cartilage was removed from animals that were subsequently euthanized by an overdose of anesthesia. The cartilage was cut into thin slices, washed with sterilized phosphate-buffered saline (PBS), and soaked in 5\% penicillin-streptomycin (Sigma, St. Louis, MO, USA) for 15 $\mathrm{min}$. The cartilage slices were washed with PBS to remove residual antibiotic solution and digested with $0.02 \%$ type II collagenase (Sigma) in Dulbecco's Modified Eagle's Medium (DMEM; HyClone, Logan, UT, USA) for 2 hours in a $37^{\circ} \mathrm{C}$ water bath. The digested cartilage was collected and centrifuged. The pellet was resuspended in DMEM and filtered through $70-\mu \mathrm{m}$ nylon mesh. The resultant chondrocytes were cultured in DMEM supplement with $10 \%$ fetal bovine serum and $1 \%$ penicillin-streptomycin in a $5 \%$ $\mathrm{CO}_{2} / 95 \%$ air at $37^{\circ} \mathrm{C}$. The cultured medium was replaced with fresh DMEM containing 10\% fetal bovine serum and
$1 \%$ penicillin-streptomycin to three times weekly. All experiments were performed when cells reached confluence within the first passage.

\section{Low intensity pulsed ultrasound stimulation}

LIPUS (Exogen 4000+; Smith \& Nephew Inc., Memphis, TN, USA) at a frequency of $1.5 \mathrm{MHz}$ was applied to the chondrocytes after being cultured for 72 hours. The US parameters included a spatial-average temporal-average output intensity of $30 \mathrm{~mW} / \mathrm{cm}^{2}$. The frequency was $1.5 \mathrm{MHz}$ with a $200 \mu$ s tone burst repeated at $1.0 \mathrm{kHz}$. Each 6-well plate of the LIPUS group was placed on an ultrasonic transducer [17]. After the plate cover had been removed, an anti-reflection chamber was placed in each well while taking care to avoid producing air bubbles. LIPUS was applied to the chondrocytes after 24 hours in culture through the bottom of the culture dish that had been placed between the LIPUS transducer and the dish. LIPUS was administered every day during the span of this experiment. The control plates were handled in the same manner without LIPUS. Thereafter, the cultured cell was harvested after 3 days.

\section{Cell proliferation}

Cell viability was analyzed using a 3-[4,5-dimethylthiazol-2-yl]-2,5 diphenyl tetrazolium bromide (MTT) assay. Tetrazolium salts such as MTT are metabolic by mitochondroal dehydrogenases to form a blue formazen dye and are, therefore, useful for the measurement of cell viability. The cell were gently washed with Hanks' balanced salt solution (Sigma), and exposed to rat primary chondrocyte. After washing the cells, culture medium containing $0.5 \mathrm{mg} / \mathrm{ml}$ of MTT was added to each well. The cells were incubated for 2 hours at $37^{\circ} \mathrm{C}$, the supernatant was removed and the formed formazen crystals in viable cells were solubilized with $110 \mathrm{ml}$ of dimethl sulfoxide. A $100 \mathrm{ml}$ aliquot of each sample was then translated to 96 well plates and the absorbance of each well was measured at $550 \mathrm{~nm}$ with the enzyme-linked immunosorbent reader (Bio-Rad Instrument, Hercules, CA, USA). The data were expressed as a percentage of control measure in the absence of rat primary chondrocyte [18].

\section{Western blotting analysis}

For the western blotting analysis of the dish cultured for 1 week, cartilage tissues specimens were harvested 2 hours after the last LIPUS and were cut into smaller pieces. Chondrocytes were pretreated with the p38 inhibitor 
(SB203580; Cell Signaling Technology, Lakewood, NJ, USA), followed by stimulation with LIPUS. Each sample was then incubated for about 8 hours in the DMEM (HyClone) supplemented with $0.1 \%$ type-II collagenase (Worthington Biochemical Co., Lakewood, NJ, USA), $10 \%$-fetal bovine serum (Equitech-Bio Inc., Lakewood, $\mathrm{NJ}$, USA) and antibiotics. The chondrocytes were then isolated, washed with culture medium, and collected by centrifugation $\left(2,000 \mathrm{rpm}, 37^{\circ} \mathrm{C}, 5 \mathrm{~min}\right)$. After the supernatant medium was removed, the cells were rinsed with $200 \mu 1$ PBS, filtered by centrifugation, and added to a $200 \mu 1$ aliquot of $2 \times$ sample buffer ( $62.5 \mathrm{mmol} / \mathrm{l}$ Tris- $\mathrm{HCl}(\mathrm{pH} 6.8)$, $2 \%$ sodium dodecyl sulphate (SDS), $10 \%$ glycerol, 50 $\mathrm{mmol} / 1$ dithiothreitol, $0.01 \%$ bromophenol blue). The cell lysates were then boiled for 10 minutes at $75^{\circ} \mathrm{C}$. Equal amounts of the protein were distributed on a $10 \%$ SDS-polyacrylamide gel at $200 \mathrm{~V}, 25 \mathrm{~mA}$ for 80 minutes and were transblotted to nitrocellulose membranes (Millipore, Billerica, MA, USA) using a wet transfer system (BIO-RAD, Hercules, CA, USA) at $200 \mathrm{~V}, 150 \mathrm{~mA}$ for 60 minutes. The membranes were blocked with blocking buffer ( $5 \%$ skimmed milk in tris-buffered saline and $0.05 \%$ Tween
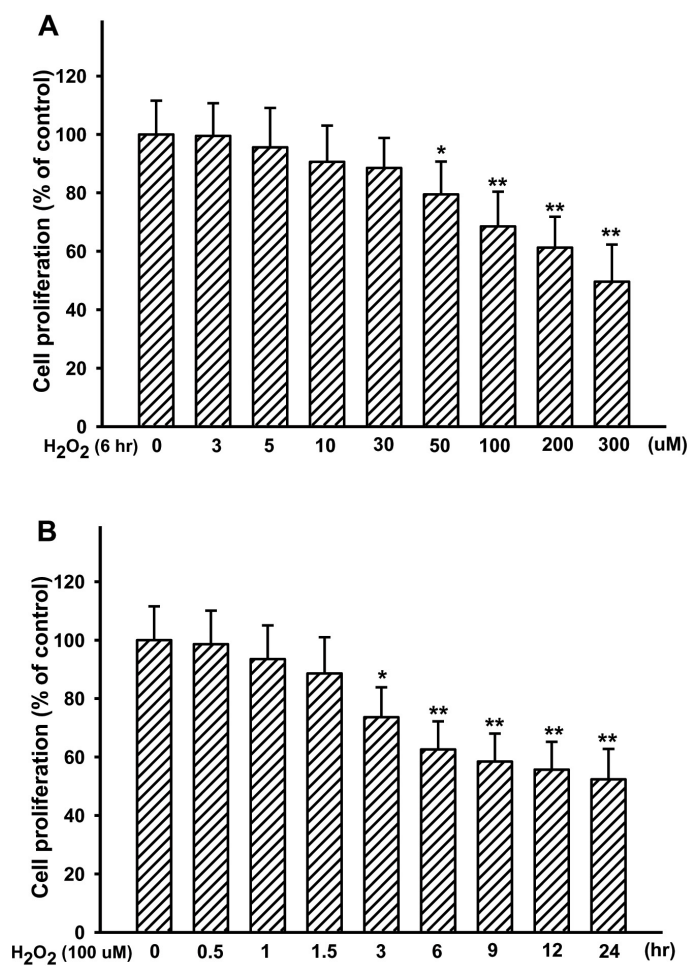

Figure 1. Time and dose response of $\mathrm{H}_{2} \mathrm{O}_{2}$ on cell proliferation. Values are mean \pm standard error of three independent experiments with triplicate dishes. ${ }^{*} p<0.05$ vs. control. ${ }^{* *} p<0.01$ vs. control.
20 and Blocking One-P; Nacalai Tesque Inc., Kyoto, Japan) and were incubated with the anti-phospho-p38 MAPK (Santa Cruz Biotechnology, Dallas, TX, USA). After incubation with the corresponding horseradish peroxidaseconjugated secondary antibodies $(1 / 5,000)$, membranes were finally incubated with a chemiluminescent reagent (Perkin Elmer Life Science, CA, USA) and the signals produced were recorded on X-ray film (BIOMAX XAR Film, Rochester, NY, USA) for a densitometric analysis.

\section{Data analysis}

Data analysis was performed with PASW Statistics 18.0 (IBM Co., Armonk, NJ, USA). All of the data were expressed as mean \pm standard deviation. The difference between the two mean values was analyzed by the Student's t-test. Values of $p<0.05$ were considered as significantly different.

\section{Results}

To examine the effect of LIPUS on rat chondrocytes, the cell viability of the chondrocytes in the presence of $\mathrm{H}_{2} \mathrm{O}_{2}$ was determined. The dependence of the inhibitory effect of oxidative stress on the $\mathrm{H}_{2} \mathrm{O}_{2}$ concentration ( 0 to $300 \mu \mathrm{M}$ ) and time ( 0 to 24 hours) was examined. Figure 1 shows that $\mathrm{H}_{2} \mathrm{O}_{2}$ added at levels $>50 \mu \mathrm{M}$ and 3 hours for significantly inhibited cell viability $(p<0.05)$. Figure 2 shows that the

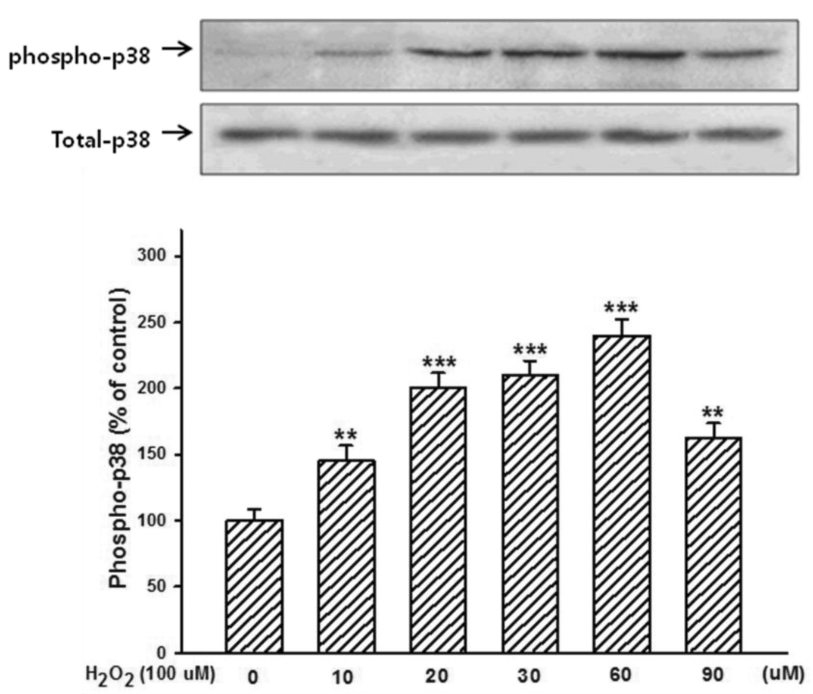

Figure 2. Dose-dependent effects of $\mathrm{H}_{2} \mathrm{O}_{2}$ phosphorylation of $\mathrm{p} 38$ mitogen-activated protein kinase. Values are mean \pm standard error of three independent experiments with triplicate dishes. ${ }^{* *} p<0.05$ vs. control. ${ }^{* * *} p<0.01$ vs. control. 


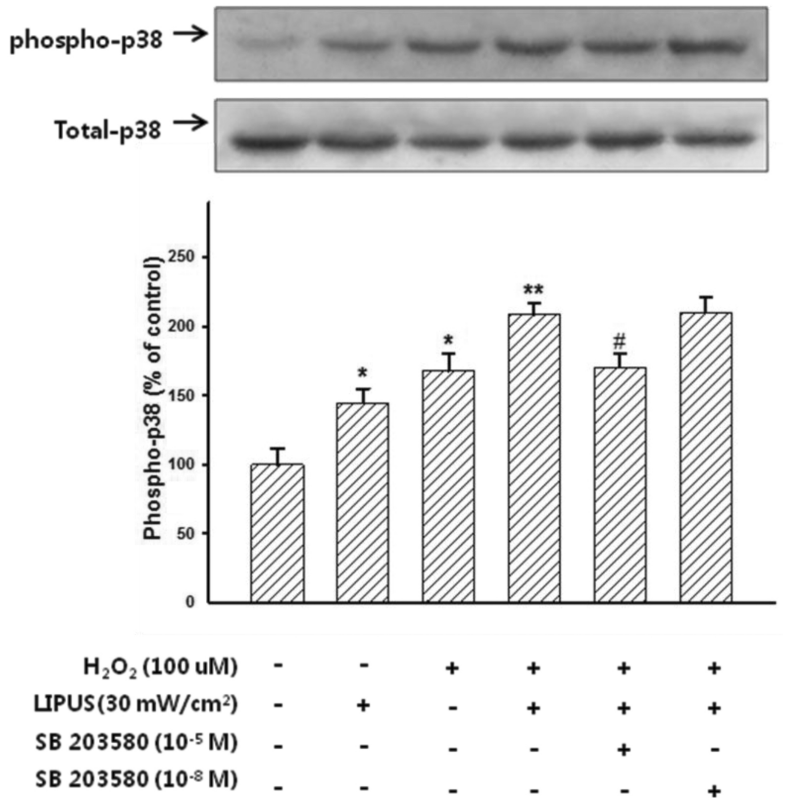

Figure 3. Effect of SB203580 on $\mathrm{H}_{2} \mathrm{O}_{2}$ and low-intensity pulsed ultrasound (LIPUS) induced phosphorylation of p38 mitogen-activated protein kinase. ${ }^{*} p<0.05$ vs. control, ${ }^{* *} p<0.05$ vs. LIPUS or $\mathrm{H}_{2} \mathrm{O}_{2}$ alone. ${ }^{*} p<0.05$ vs. LIPUS and $\mathrm{H}_{2} \mathrm{O}_{2}$.

p38 MAPK phosphorylation occurred at a significantly increased rate after $\mathrm{H}_{2} \mathrm{O}_{2}$ treatment $(p<0.05)$. Western blot analysis results showed increase phosphorylation of p38-MAPK according to $\mathrm{H}_{2} \mathrm{O}_{2}$ concentration dependent compared with the control group $(p<0.05)$. Moreover, the phosphorylation of $\mathrm{p} 38$-MAPK by $\mathrm{H}_{2} \mathrm{O}_{2}$ and LIPUS was almost completely attenuated by the p38-MAPK inhibitor, SB203580 ( $p<0.05$; Figure 3$)$.

\section{Discussion}

Half of the world's population aged $\geq 65$ years have arthritis $[19,20]$. OA is commonly described as a non-inflammatory disease that distinguishes it from other inflammatory arthritis types such as rheumatoid arthritis [3]. These joint tissue changes impair the ability of chondrocytes to synthesize the surrounding extracellular matrix. Accordingly, the ability to maintain cartilage homeostasis is decreased in aged chondrocytes, and matrix proteins are smaller and more irregular [21]. The pathological mechanism of OA is closely associated with excessive mechanical and oxidative stress, but its underlying mechanisms have not been fully clarified. The present study investigated the effect of LIPUS in cell proliferation and related signal mechanisms that are implicated in OA using rat chondrocytes subjected to $\mathrm{H}_{2} \mathrm{O}_{2}$ induced oxidative stress.

Mechanisms of the pathogenesis of OA such as oxidative stress and free radical generation, have been suggested to be important factors involved in OA [22]. Suitable amounts of oxidative stress have a variety of biological effects on various cell types. Free radical exposure is known to promote cellular senescence and apoptosis. However, the presence of $\mathrm{H}_{2} \mathrm{O}_{2}$ may produce reactive oxygen species and nitrous oxygen species in addition to inducing the apoptosis of chondrocytes $[23,24]$. Free radicals are related to many chronic inflammatory diseases [25]. Thus, $\mathrm{H}_{2} \mathrm{O}_{2}$ may be an important factor involved in the pathological mechanism of OA. In our study, cell proliferation showed significantly decreased viability after $\mathrm{H}_{2} \mathrm{O}_{2}$ treatment. In general the adult articular cartilage shows slow cellular turnover. In this turnover, new optimal tissue bearing mechanical stress is built and damaged cells subjected to oxidative stress are removed. Thus, one of the most important therapeutic significance in OA research is that adequate amounts of mechanical stress may prompt articular cartilage repair [26,27].

The MAPK family consists of proline-directed serine/threonine kinases and can be divided into two basic groups. Extracellular regulated kinases 1 and 2 are stimulated by mitogens and involved in cell growth and differentiation. In contrast, Jun N-terminal kinases and p38 MAPK are stimulated by cellular stress [28]. The p38 MAPK pathways are known signal transducers that regulate proliferation and differentiation. The role of p 38 MAPK signaling in cartilage development has been reported to be involved in the maturation of growth plate chondrocytes [29]. Our results showed that activation of $\mathrm{p} 38$-MAPK pathways in cell subjected to oxidative stress after LIPUS stimulation was decreased by the SB203580 treatment. However, the literature is ambiguous regarding the influence of LIPUS on articular chondrocytes and the possible acceleration of the chondrogenic pathways. Some experimental studies have shown evidence that LIPUS results in enhanced cartilage repair during fracture healing and callus distraction [30,31].

Our results suggest the involvement of $\mathrm{p} 38$ MAPK in the regulation of apoptosis and survival after LIPUS. However, further experiments should be performed to precisely determine the involvement of the different pathways.

\section{References}

1. Goldring MB, Goldring SR. Osteoarthritis. J Cell Physiol 2007;213:626-34. 
2. Praemer A, Furner S, Rice DP. Musculoskeletal conditions in the United States. Rosemont (IL): American Academy of Orthopaedic Surgeons; 1999.

3. Hassanali SH. Osteoarthritis: a look at pathophysiology and approach to new treatments: a review. East Afr orthop J 2011;5: 51-7.

4. Bijlsma JW, Berenbaum F, Lafeber FP. Osteoarthritis: an update with relevance for clinical practice. Lancet 2011;377:2115-26.

5. Mascarin NC, Vancini RL, Andrade ML, Magalhães Ede P, de Lira CA, Coimbra IB. Effects of kinesiotherapy, ultrasound and electrotherapy in management of bilateral knee osteoarthritis: prospective clinical trial. BMC Musculoskelet Disord 2012; 13:182.

6. Adams T, Band-Entrup D, Kuhn S, Legere L, Mace K, Paggi A, et al. Physical therapy management of knee osteoarthritis in the middle-aged athlete. Sports Med Arthrosc 2013;21:2-10.

7. Correia C, Pereira AL, Duarte AR, Frias AM, Pedro AJ, Oliveira JT, et al. Dynamic culturing of cartilage tissue: the significance of hydrostatic pressure. Tissue Eng Part A 2012;18:1979-91.

8. D'Andrea P, Vittur F. Ca2+ oscillations and intercellular $\mathrm{Ca} 2+$ waves in ATP-stimulated articular chondrocytes. J Bone Miner Res 1996;11:946-54.

9. Farnsworth NL, Antunez LR, Bryant SJ. Dynamic compressive loading differentially regulates chondrocyte anabolic and catabolic activity with age. Biotechnol Bioeng 2013;110:2046-57.

10. Ito A, Aoyama T, Yamaguchi S, Zhang X, Akiyama H, Kuroki H. Low-intensity pulsed ultrasound inhibits messenger RNA expression of matrix metalloproteinase-13 induced by interleukin- $1 \beta$ in chondrocytes in an intensity-dependent manner. Ultrasound Med Biol 2012;38:1726-33.

11. Korstjens CM, van der Rijt RH, Albers GH, Semeins CM, Klein-Nulend J. Low-intensity pulsed ultrasound affects human articular chondrocytes in vitro. Med Biol Eng Comput 2008;46: 1263-70.

12. Naito K, Watari T, Muta T, Furuhata A, Iwase H, Igarashi M, et al. Low-intensity pulsed ultrasound (LIPUS) increases the articular cartilage type II collagen in a rat osteoarthritis model. J Orthop Res 2010;28:361-9.

13. Lv Y, Zhao P, Chen G, Sha Y, Yang L. Effects of low-intensity pulsed ultrasound on cell viability, proliferation and neural differentiation of induced pluripotent stem cells-derived neural crest stem cells. Biotechnol Lett 2013;35:2201-12.

14. Martinez de Albornoz P, Khanna A, Longo UG, Forriol F, Maffulli N. The evidence of low-intensity pulsed ultrasound for in vitro, animal and human fracture healing. Br Med Bull 2011; 100:39-57.

15. Azuma Y, Ito M, Harada Y, Takagi H, Ohta T, Jingushi S. Low-intensity pulsed ultrasound accelerates rat femoral fracture healing by acting on the various cellular reactions in the fracture callus. J Bone Miner Res 2001;16:671-80.

16. Goldring MB. Update on the biology of the chondrocyte and new approaches to treating cartilage diseases. Best Pract Res Clin Rheumatol 2006;20:1003-25.

17. Iwabuchi S, Ito M, Hata J, Chikanishi T, Azuma Y, Haro H. In vitro evaluation of low-intensity pulsed ultrasound in herniated disc resorption. Biomaterials 2005;26:7104-14.

18. Denizot F, Lang R. Rapid colorimetric assay for cell growth and survival. Modifications to the tetrazolium dye procedure giving improved sensitivity and reliability. J Immunol Methods 1986; 89:271-7.

19. Kotlarz H, Gunnarsson CL, Fang H, Rizzo JA. Insurer and out-of-pocket costs of osteoarthritis in the US: evidence from national survey data. Arthritis Rheum 2009;60:3546-53.

20. Buckwalter JA, Roughley PJ, Rosenberg LC. Age-related changes in cartilage proteoglycans: quantitative electron microscopic studies. Microsc Res Tech 1994;28:398-408.

21. Dudhia J. Aggrecan, aging and assembly in articular cartilage. Cell Mol Life Sci 2005;62:2241-56.

22. Yudoh K, Nguyen vT, Nakamura H, Hongo-Masuko K, Kato T, Nishioka K. Potential involvement of oxidative stress in cartilage senescence and development of osteoarthritis: oxidative stress induces chondrocyte telomere instability and downregulation of chondrocyte function. Arthritis Res Ther 2005;7:R380-91.

23. Takahashi T, Kitaoka K, Ogawa Y, Kobayashi T, Seguchi H, Tani $\mathrm{T}$, et al. Lysosomal dysfunction on hydrogen peroxide-induced apoptosis of osteoarthritic chondrocytes. Int J Mol Med 2004;14: 197-200.

24. Asada S, Fukuda K, Nishisaka F, Matsukawa M, Hamanisi C. Hydrogen peroxide induces apoptosis of chondrocytes; involvement of calcium ion and extracellular signal-regulated protein kinase. Inflamm Res 2001;50:19-23.

25. Ziskoven C, Jäger M, Kircher J, Patzer T, Bloch W, Brixius K, et al. Physiology and pathophysiology of nitrosative and oxidative stress in osteoarthritic joint destruction. Can J Physiol Pharmacol 2011;89:455-66.

26. Torzilli PA, Bhargava M, Chen CT. Mechanical loading of articular cartilage reduces il-1-induced enzyme expression. Cartilage 2011;2:364-73.

27. Sobol E, Shekhter A, Guller A, Baum O, Baskov A. Laser-induced regeneration of cartilage. J Biomed Opt 2011;16:080902.

28. Kyriakis JM, Avruch J. Mammalian mitogen-activated protein kinase signal transduction pathways activated by stress and inflammation. Physiol Rev 2001;81:807-69.

29. Stanton LA, Sabari S, Sampaio AV, Underhill TM, Beier F. p38 MAP kinase signalling is required for hypertrophic chondrocyte differentiation. Biochem J 2004;378:53-62.

30. Duarte LR. The stimulation of bone growth by ultrasound. Arch Orthop Trauma Surg 1983;101:153-9.

31. Gebauer GP, Lin SS, Beam HA, Vieira P, Parsons JR. Low-intensity pulsed ultrasound increases the fracture callus strength in diabetic BB Wistar rats but does not affect cellular proliferation. J Orthop Res 2002;20:587-92. 